\title{
Prioritarianism in Health-Care: RESISTING THE REDUCTION TO UTILITARIANISM
}

\author{
- Massimo Reichlin -
}

\begin{abstract}
Tännsjö's book Setting Health-Care Priorities defends the view that there are three main normative theories in the domain of distributive justice, and that these theories are both highly plausible in themselves, and practically convergent in their normative conclusions. All three theories (utilitarianism, the maximin/leximin theory and egalitarianism) point to a somewhat radical departure from the present distribution of medical resources: in particular, they suggest redirecting resources from marginal life extension to the care of mentally ill patients. In this paper I wish to argue, firstly, that prioritarianism should not be considered as an amendment to utilitarianism, as it is in Tännsjö's view, but as a distinctive fourth option. This can best be appreciated if we focus on a reading of the theory that emphasizes its derivation from egalitarianism and its attempt to develop an intermediate approach between utilitarian and egalitarian intuitions. Secondly, in response to Tännsjö's central objection to prioritarianism, I will argue that the theory does not apply in intrapersonal cases but is only relevant for decisions regarding the interpersonal distribution of benefits. Finally, I will suggest that a practical convergence of the four theories on specific issues such as artificial reproduction or mood enhancement is far less likely than Tännsjö seems to believe.
\end{abstract}

Keywords: distributive justice; utilitarianism; egalitarianism; maximin/leximin theory; prioritarianism.

Published online: 23 September 2021

\section{Introduction}

The problem of establishing priorities for the allocation of health-care resources is pervasive in contemporary medicine, as the present Covid-19 pandemic has made abundantly clear. The contribution of normative ethical theories to clarifying the values at stake and suggesting consistent solutions to pressing practical needs cannot be overestimated. Torbjörn Tännsjö's book is therefore a most important and timely contribution to the bioethical debate, and to practical decision-making in the present predicament. The book presents an in-depth discussion of various abstract theories, together with a detailed analysis of their consequences when applied to several domains in contemporary health-care. In all cases, the framework offered by the author is rich in both the philo-

Massimo Reichlin

Faculty of Philosophy

Vita-Salute San Raffaele University

e-mail: reichlin.massimo@unisr.it 
sophical literature discussed and the epidemiological details on which the philosophical discussion is based.

Tännsjö's strategy in this book can be compared to that adopted by two philosophers who are certainly among those to have influenced him. Henry Sidgwick, in The Methods of Ethics, began by noticing the existence of three main methods for reaching normative conclusions in common sense morality, and tried to show the convergence of two of them on a philosophically refined version of utilitarianism. ${ }^{1}$ Likewise, Derek Parfit's On What Matters tries to show the convergence of three main normative traditions in contemporary ethics - namely, Kantianism, rule consequentialism and contractualism - towards what he calls the 'triple theory', centering on principles that are optimific, universally willable, and not reasonably rejectable. ${ }^{2}$ In a similar vein, Tännsjö attempts to show a convergence of theories in the area of distributive justice - with the difference that such a convergence takes place mainly at a practical level, while it is acknowledged that, at the theoretical level, notable differences persist. We might say that Tännsjö somehow improves on the work of his two influential models: while Sidgwick managed to synthesize two theories (with egoism remaining as a non-refuted alternative), and Parfit did the same with three, Tännsjö aims to show the practical convergence of four main approaches to distributive justice. Or at least this is how I will conceptualize his attempt. In fact, while Tännsjö argues that the most plausible contenders are the maximin/leximin theory, egalitarianism, and utilitarianism, with prioritarianism as a possible amendment of this last, I will suggest, in sections 3 and 4 of the present discussion, that prioritarianism should be conceived as a distinctive fourth option. In section 5, I will show that, also because of this irreducibility of prioritarianism to (a variation of) utilitarianism, the practical convergence of the four theories is less complete than Tännsjö's account would suggest. In the following section I will summarize Tännsjö's conclusions on the respective merits of the theories.

\section{Tännsjö's evaluation of the theories}

Although Tännsjö seeks to show the practical convergence of the four theories, he clearly sides with utilitarianism. Rawls' approach, which he dubs 'the maximin/leximin theory', is unacceptable to him, primarily because of its extreme ageism: this theory suggests prioritizing the young even in situations in which an elderly patient might benefit more from treatment. Secondly, the maximin/leximin theory does not take people's suffering seriously enough. By concentrating on entire lives, it grants priority to the individual who has experienced less happiness in her life thus far; this entails that the present severe suffering of someone who is comparatively better off than another will not be considered sufficient reason for providing her with treatment. Finally, since the worst off may also be the least talented in transforming resources into happiness, it may easily happen that they drain all the available resources without thereby achieving any considerable happiness; in these cases, they seem to act as 'utility thieves'.

\footnotetext{
${ }^{1}$ Sidgwick (1981): 496-509.

2 Parfit (2011): 411-419.
} 
Egalitarianism is less radical in the favor it accords to the least well off, since it disallows them to drain all the available resources, and only accepts prioritizing them to the extent that this realizes equality; as noted by Tännsjö, "it doesn't leave room to utility thieves." ${ }^{3}$ However, due to its inclination to take decisions on the basis of entire lives, egalitarianism too disregards the importance of human suffering. Moreover, radical forms of egalitarianism that conceive of inequalities as bad per se are exposed to the 'levelling-down objection', i.e., they must accept that an unequal distribution is somehow worse than an equal one, even if everyone in the former ends up better off. This seems counterintuitive, since it is arguable that a fair distribution should avoid the most significant disparities of welfare, without worsening anyone's situation or losing sight of individual merit.

These are among the reasons that justify Tännsjö's conclusion that we should

"give up on the maximin/leximin theory. The theory allows that all resources can be drained by a single person who, relatively speaking, is very poorly off and who cannot gain much from our attention except at an enormous cost. This is not acceptable. [...] Moreover, I find it problematic that both the maximin/leximin theory and egalitarianism are theories overly insensitive to suffering. This, again, in my view, is not acceptable."4

These objections are powerful. Nonetheless, Tännsjö acknowledges that there are well-known objections to utilitarianism as well, and concludes that, all things considered, all three theories are at least highly plausible.

As far as prioritarianism is concerned, Tännsjö treats it as an amendment to utilitarianism, and in most circumstances decidedly rejects it. Unlike egalitarianism, he says, prioritarianism is preoccupied with absolute (rather than relative) levels of happiness; in fact, it adjusts utilitarianism's ambition to maximize happiness with an attempt to distribute it in such a way that the worst off are given special consideration. Increments in the happiness of such people are therefore given more moral weight than increments to the happiness of the better off, because happiness has decreasing marginal importance. Moreover, prioritarianism does not risk falling into the insensitivity to suffering that can be attributed to the maximin/leximin theory and to egalitarianism; in fact, at least in its most charitable interpretation, it determines the respective values of increments of happiness by concentrating on the present condition of the competing individuals, not on the total happiness of their entire lives. What is most important, according to prioritarianism, is that people presently experiencing special difficulties and severe suffering are given due consideration, for it is suffering that makes a special and urgent appeal to our moral responses. Should prioritarianism concentrate on entire lives in order to identify the worst off, then it would become extensionally equivalent to egalitarianism, at least in the version that avoids any levelling down.

\footnotetext{
3 Tännsjö (2019): 66.

4 Tännsjö (2019): 70.
} 
In the interpretation focusing on present conditions, prioritarianism is a plausible theory. Nonetheless, according to Tännsjö, it also faces decisive objections, to which I will return in the next section. Therefore, utilitarianism seems to enjoy an edge on all rival theories.

\section{Prioritarianism between utilitarianism and egalitarianism}

My main aim in this paper is to discuss Tännsjö's characterization of prioritarianism. On the one hand, I agree with his 'actualist' or 'synchronic' reading and believe that such a reading is to be preferred, especially in the context of setting health-care priorities. In this domain, decisions should not aim at pursuing a general equalization of welfare among citizens' lives; such a goal - if it is one - calls for other strategies, such as taxation policies and social insurance. The setting of health-care priorities, particularly within the framework of a national health-care system as presupposed by Tännsjö, aims to meet the present medical needs of differently wealthy individuals, and to do so in a justifiable manner; therefore, it should not focus on whether one patient has had an overall happier life than another, but rather on whether her present need is greater. (This, however, does not exclude the possibility that, in cases of chronic disease, the present suffering of one patient may be increased by virtue of her having already experienced such suffering for several years). On the other hand, it seems to me that Tännsjö's account fails to do justice to the specificity of the prioritarian approach by reducing it to an amendment to utilitarianism. I would suggest that the merits of such an approach may best be appreciated when it is conceived as an independent account. The alternative characterization that I will propose considers prioritarianism as an amendment to egalitarianism, rather than to utilitarianism; moreover, it does not see it as a theory of general normative ethics, parallel to utilitarianism, but rather as a more specific view, only concerned with the distribution of welfare and other resources in conflict cases. This will allow a very straightforward response to Tännsjö's main objection to prioritarianism. Such a difference in the interpretation of prioritarianism is not surprising, since different versions of it have been proposed and, as noted by Tännsjö himself,

"What we meet with here is really a family of very different views with one thing in common: the idea that unhappiness has an increasing marginal moral importance." 5

As for the first point, Tännsjö writes that prioritarianism "is aggregative in the same manner that utilitarianism is, it is only that it urges us to maximize a weighted sum total of happiness." ${ }^{6}$ On the contrary, I suggest that the most defensible versions of prioritarianism do not emphasize the maximization of (weighted) happiness, but rather the urgency of providing help to people who are badly off. As noted by Arneson, "The root idea of prioritarianism is that one ought as a matter of justice to aid the unfortunate, and the more badly off someone is, the more urgent is the moral imperative to aid." ${ }^{7}$ The focus

\footnotetext{
5 Tännsjö (2019): 50.

6 Tännsjö (2019): 50.

7 Arneson (2000): 343.
} 
of the view, in other words, is not the maximization of weighted benefits, but a concern for the peculiar urgency of the needs of those who are relatively worse off. This results not in the pursuit of maximal aggregate happiness, but in the moral imperative to treat all persons as deserving protection against basic forms of suffering and unhappiness, consistent with the duty not to waste the available resources.

According to this interpretation, prioritarianism shares its basic intuition with the egalitarian approach: if someone is much worse off than others, then he or she has a stronger claim to receive whatever benefit is being distributed, and priority should therefore be attributed to him or her. As noted by Parfit, ${ }^{8}$ prioritarianism parts company with egalitarianism in that it does not attribute value to the relation of equality in itself, but the theory has a comparative dimension as well, since it attributes intrinsic value to a benefit's falling at a lower rather than higher level. ${ }^{9}$ In other words, the rightness of a distribution is a function of a comparative evaluation of the levels of welfare or resources enjoyed by the competing individuals, and the fact that someone is comparatively worse off is a reason (at least pro tanto) to prioritize in her favor. Moreover, prioritarianism also differs from utilitarianism in posing limits on aggregation. For example, it does not sanction providing small benefits to a very large set of better off people rather than bestowing a significant benefit on one worse off individual; ${ }^{10}$ while the sum total of the former may exceed the value of the latter, the focus of the approach is not on the maximization of welfare, but rather on granting people basic protection against suffering and unhappiness. What justifies prioritizing the worst off is not the size of the benefit that can be realized, but the strength and urgency of their need. Prioritarianism does not consider the fact that someone is enjoying a level of happiness higher than mine as inherently bad for me; what is bad, and wrong, is that I am not given relief from a particularly negative situation because allocating the resources to another individual who is much better off than me produces a higher surplus of happiness for him. If this is the theory's basic insight, then prioritarianism must be distinguished from both utilitarianism and egalitarianism and can be rightly considered yet another competitor.

Evidence in favor of this interpretation of prioritarianism, alternative to Tännsjö's reading, is offered in a paper by Nagel in which the view was originally proposed. Nagel discussed a dilemma between moving to a semi-rural suburb, thus granting a larger benefit to one's "normal and quite happy" child, and moving to the city, in order to grant a smaller benefit to another child who is suffering from a painful handicap. His idea was that

"It is more urgent to benefit the second child, even though the benefit we can give him is less than the benefit we can give the first child. This urgency is not necessarily decisive. It may be outweighed by other considerations, for equality is not the only value." 11

\footnotetext{
${ }^{8}$ Parfit (1997): 213-214.

${ }_{9}$ Holtug (2007): 132.

${ }^{10}$ On this point see Fleurbaey, Tungodden, Vallentyne (2009).

${ }^{11}$ Nagel (1978): 23.
} 
Nagel does not say that, considering diminishing marginal utility, benefitting the second child produces more benefits. He says that it produces less benefit, and yet, moving to the city is the right thing to do, because it is an egalitarian decision. The fact is that the reasons in favor of benefiting the second child are stronger than those in favor of benefiting the first because the second experiences a far worse starting condition. At the same time, Nagel says that the urgency of benefiting the worse off child can be outweighed, thus acknowledging that the value of equality is not paramount, and implicitly rejecting egalitarianism. It was Parfit who later explicitly made such a move. He noted that, according to prioritarianism, some people's being worse off is not per se unjust, because prioritarianism rejects the inherently comparative dimension of justice. However, Parfit also distinguished the priority view from utilitarianism: in fact, while utilitarians assume that the moral importance of each benefit depends only on its greatness, prioritarians accept that "benefiting people matters more the worse off these people are." 12 The ensuing literature has often discussed whether prioritarianism is a part of the egalitarian tradition or not, and several writers have claimed that prioritarianism is in fact one version of egalitarianism. ${ }^{13}$ For the present purposes, there is no need to insist on prioritarianism's belonging to the family of egalitarian theories, as long as the egalitarian flavor of its basic idea is acknowledged. Prioritarianism shares the egalitarian concern for those who are suffering most, or whose basic needs are not being met; however, it avoids prizing equality per se, and therefore eschews standard problems of egalitarianism such as the levelling down objection. This shows that, while deriving from egalitarianism, the theory is distinct from it, and differs from utilitarianism by attributing value not only to the quantitative increase in aggregate welfare, but also to the fact that the benefits fall on individuals in dire need. As noted by Holtug, "the prioritarian ascribes intrinsic value to compound states of affairs, each consisting of the state that a benefit of a certain size befalls an individual and the state that the individual is at a particular welfare level, where this value increases when the size of the benefit increases but decreases when the level of welfare increases." ${ }^{14}$ By integrating this distributive concern into its appreciation of benefits, prioritarianism accepts a pluralistic account of value, in which both welfare and equality matter. This marks a significant difference with respect to utilitarianism and its monistic conception of value and justifies considering it an independent approach.

\section{Prioritarianism as a theory of distributive justice}

The second difference in my characterization of prioritarianism has to do with the way in which it tackles examples of intrapersonal and interpersonal comparisons of benefit. According to one critique, ${ }^{15}$ there is a morally important difference between the two, but prioritarianism is unable to account for it. Imagine a patient who is risking very severe disability and has to choose between a treatment that may either restore perfect health or result in very severe disability, and another that may result either in severe or in slight

12 Parfit (1997): 213.

${ }^{13}$ Arneson (2000); Jensen (2003); Fleurbaey (2015).

${ }^{14}$ Holtug (2007): 132.

${ }^{15}$ Otsuka, Voorhoeve (2009). 
disability; in a parallel interpersonal case, our intervention could either bring patient A from very severe to severe disability, or patient B from slight disability to perfect health. In the first case we tend to be indifferent, provided that the patient is too, while in the second we feel that we ought to treat patient A. According to prioritarianism, however, we should not be indifferent in either case: given the peculiar value attributed to severe disability, we should choose the second option in the intrapersonal case, just as we should prioritize the worse off patient in the interpersonal one. This alleged difficulty of prioritarianism is recalled in Tännsjö's "crucial test", which offers "a strong argument against prioritarianism which should stop us from having any hope that it might be on the right track."16 The situation discussed by Tännsjö is that of a patient who can live one more year with ups and downs and sessions of painful therapy; the extra weight given to the downs will determine a negative value for this added year, suggesting that her life should not be saved. While we do the right thing from a utilitarian point of view if we save the life of this patient, "according to the prioritarian view, we must conclude that irrespective of whether there were any competing needs to tend to we have wasted resources. We have used our resources in a way that is proscribed by the theory." 17 This conclusion is problematic, according to Tännsjö, because in both cases we have overriding reasons to decide based on utilitarian calculations: that is, we should opt for the solution that ensures the highest expected utility. In fact, our intuition that severely disabled people should be prioritized, according to Tännsjö, is based on the false assumption of diminishing marginal utility in medical resources; actually, there is no such marginal reduction, and, in some cases, it could even be the other way around.

Prioritarians have sometimes reacted to the charge of not accounting for the difference between intrapersonal and interpersonal cases by denying the existence of such a difference, and thereby accepting the application of prioritarian weighting to intrapersonal trade-offs. ${ }^{18}$ This reply indicates a willingness to bite the bullet and accept that the additional year of life in Tännsjö's "crucial test" may be not worth living after all. I wish to suggest a different reply designed to show that, in the version that best captures its basic insight, prioritarianism does not face the problem raised by Tännsjö.

The reply consists in saying that prioritarianism only applies to the distribution of benefits among different individuals. Evidence for this can be furnished by noting that, in Nagel's account, the view is invoked in order to adjudicate among competing claims by different individuals. In particular, if we return to Nagel's example, it is clear that he suggests granting priority to the less well-off child precisely because we are considering two different persons with different lives to live, and the greater benefits conferred to the healthy child cannot compensate for the suffering of the sick one. This is perfectly compatible with saying - and indeed seems to require - that when it comes to decisions concerning your own individual welfare, you can decide to compensate between the ups and the downs in your life, because you are one and the same person. In so far as the theory offers an insight into assessing the relative urgency of the synchronic claims of different individuals, it does not imply anything when it comes to the diachronic interests

\footnotetext{
16 Tännsjö (2019): 84.

17 Tännsjö (2019): 84-85.

18 O’Neill (2012); Segall (2016): 155-161.
} 
of the same individual. The peculiarly negative value of severe suffering justifies giving priority to treating someone who is experiencing it, because her needs are more urgent; it does not dictate any decision when the matter concerns only one's own welfare and a prudential appreciation of the relative odds.

In health care contexts, the theory establishes priorities of intervention when resources are finite, and a choice must be made between benefiting one patient or another; but it offers no advice when one has to weigh the pros and cons of a therapy that promises to extend her own life at a certain cost. If nothing else, this is because applying prioritarian weights to the diachronic needs of one individual implies a diachronic consideration of her life from that time on; and this contrasts with Tännsjö's idea that "the value of the happiness of an individual at a moment is determined by how she fares, at this moment." 19 Therefore, I see no reason why, in situations in which only one's own individual happiness is involved, we should resort to prioritarian weightings. In contrast to utilitarianism, prioritarianism is not a general theory of morality providing normative guidance for all sorts of moral decisions, including prudential or self-regarding ones; it offers guidance in the evaluation of reasons for benefiting people, with a particular concentration on the fairness of such choices. It is therefore compatible with several consequentialist or deontological theories, as far as general normative theories are concerned. Tännsjö himself contemplates the hypothesis that "some may accept utilitarianism (with or without a prioritarian amendment) as guiding them with regard to 'imperfect' duties, but they may want to add that there are also 'perfect' duties" 20; and this is what I am here suggesting also for prioritarianism. You can, that is, appeal to prioritarianism in order to meet the requirements of the principle of beneficence appropriately, but you will need other principles, such as autonomy and moral integrity, in order to make decisions in intrapersonal cases.

Tännsjö discusses a similar objection when he considers an account by Rabinowicz that excludes the relevance of prioritarianism for intrapersonal balancing. ${ }^{21} \mathrm{His}$ reaction is to reject it as an ad hoc move, but I suggest that it is not - if we interpret the theory as an amendment to egalitarianism, rather than an amendment to utilitarianism. ${ }^{22}$ Utilitarianism is a monistic theory, suggesting the maximization of aggregate benefit as a general principle, applicable to both self-regarding and other-regarding decisions. Prioritarianism was originally proposed by Nagel and has recently been discussed by authors such as Holtug, Arneson and Fleurbaey, as a principle of fair distribution of benefits across persons. Tännsjö objects that excluding priority weights in intrapersonal cases is tantamount to declaring the irrelevance of morality for self-regarding decisions - and this is a high price, particularly if moral realism is assumed. While personally granting the assumption of moral realism, I would say that of course morality applies to self-regarding decisions, but, as noted by Parfit, ${ }^{23}$ prioritarians have recourse to other moral principles

\footnotetext{
19 Tännsjö (2019): 46.

20 Tännsjö (2019): 101.

${ }^{21}$ Rabinowicz (2002).

22 This, as already noted, is the upshot of reading the theory in the wake of authors such as Nagel (1991); Arneson (2000) and Fleurbaey (2015).

${ }_{23}$ Parfit (2012): 424. Parfit, however, accepts that prioritarianism can be used as a prudential principle.
} 
to make these decisions. As already noted, prioritarianism is not committed to a monistic view and accepts the relevance of other moral considerations. Finally, Tännsjö offers a new example of an interpersonal decision, in which we can either add a few minutes to the life of an extremely happy person, or save the life of the original patient, and suggests that, according to prioritarianism, we should choose the first option, because - given the highly negative value of the downs in the original patient's year of life - even such a small gain for the already happy person is preferable. This, however, is misleading, since it continues to apply the priority weights intrapersonally in assessing the value of saving the original patient. Contrary to Tännsjö's view, I submit that prioritarianism would suggest saving the life of the original patient, because the original patient is the one whose predicament is worse; after all, the other individual is already very happy, and our failing to add a few more minutes to that happiness cannot be wrong.

\section{On the practical convergence of the theories}

The second part of Tännsjö's book sets out to demonstrate that "even if in abstract medical thought experiments the implications from the theories differ, they point in the same direction when we assess the broad questions about priority setting in real life in health care." ${ }^{24}$ Specifically, they all point to redirecting resources from marginal life extension to the care of the mentally ill. His strategy is to compare utilitarianism and the maximin/ leximin theory, as they are the two theories that differ most in the abstract; the assumption is that, if these two converge, egalitarianism is likely do so as well, and the same holds for prioritarianism, considered as a variant of utilitarianism. In this section, many conclusions are somewhat inevitably speculative, because it is not always clear what a theory would imply in specific cases, and because few theorists have undertaken the effort to display the practical solutions endorsed by their theories in many domains of biomedicine. Nonetheless, some conclusions may seem sufficiently safe, and my impression is that they fail to justify Tännsjö's confidence in practical convergence. Moreover, considering the different characterization of prioritarianism given above, I also suggest that on some topics prioritarians may side with the maximin/leximin theory more often than with utilitarianism.

One point on which the maximin/leximin theory and utilitarianism seem far from converging is that of assisted reproduction. Tännsjö rightly notes that the former has a generally antinatalist approach, based on the possibility that the child may end up having a life worth not living; on the other hand, utilitarianism has a pronatalist attitude and seems to sanction most, if not all, forms of artificial reproduction. In fact, according to Tännsjö, both utilitarianism and prioritarianism welcome the 'repugnant conclusion': they accept, that is, that "there are two ways of making the world a better place: by increasing the happiness of existing individuals (or at least mitigating their suffering) and by creating happy persons. But the latter approach is what we take when we resort to assisted reproduction." ${ }^{25}$ It is highly controversial, however, to say that prioritarianism

\footnotetext{
24 Tännsjö (2019): ix.

25 Tännsjö (2019): 151.
} 
welcomes the repugnant conclusion. If, as I have suggested, prioritarianism is interpreted as an amendment to egalitarianism, and if by its amendment of egalitarianism it eschews the levelling down objection, ${ }^{26}$ this is because it adopts a person-affecting view of distribution: according to such a view, one distribution cannot be better than another unless there is at least someone - someone worse off than others - whose welfare is enhanced by it. As noted by Holtug: "In order for prioritarianism to imply that an outcome is intrinsically better than another, in any respect or all things considered, it would have to be better for someone, were it to obtain, or the other outcome would have to be worse for someone, were that outcome to obtain." ${ }^{27}$ It is precisely the fact that prioritarianism holds this person-affecting principle that enables it to amend egalitarianism and avoid the levelling down objection. Therefore, in the dilemma posed by the repugnant conclusion, prioritarians would favor mitigating the suffering of already existing persons, rather than compensating it by creating new happy people. ${ }^{28}$ In fact, benefiting those who are suffering betters their condition, while creating new persons betters no one's condition. Once again, the moral idea at the heart of prioritarianism presupposes the existence of at least two persons, and of some negative condition that can be bettered by our intervention. The aim of the approach is not to create a state of the world containing the greatest possible quantity of well-being, but to improve the predicament of the least well off. Therefore, it seems that prioritarianism would not sanction the generation of new individuals when the resources could be used to promote significant improvements in the conditions of already existing individuals.

In order to correct the initial impression of a radical divergence on the topic, Tännsjö argues that if we look at the supply side of the story, we can see that adherents of the maximin/leximin theory also have reasons for accepting various forms of assisted reproduction; in fact, having more children means having more contributors to the medical system. Moreover, suggesting the alternative of adoption would not be sensible, since "it is not likely that people eager to have their 'own' biological children, and who now seek assisted reproduction, would be well suited as adoptive parents." ${ }^{29} \mathrm{I}$ am not convinced by these arguments: it seems to me that the maximin/leximin theory would not assign a high priority to many forms of assisted reproduction. While in vitro fertilization for infertile couples clearly qualifies as therapy, and granting such couples children protects "normal species functioning", many other uses of reproductive technologies may seem not to be included in a 'decent minimum of health care services': ${ }^{30}$ if granting such a minimum means providing everyone with the medical resources to combat the main causes of early death, and protecting the normal range of opportunity within a given society, it is unlikely that the basic package offered by the state should include publicly financed interventions such as surrogacy or IVF in same-sex couples.

${ }^{26}$ This has been the standard view from Parfit onwards. I assume it is right, even though it has been criticized by Persson (2008). For relevant discussion, see Porter (2011).

${ }^{27}$ Holtug (2007): 143.

${ }^{28}$ Parfit also says that the prioritarianism principle "cannot be applied to cases in which, in the different possible outcomes, different people would exist" (Parfit (2012): 440).

${ }^{29}$ Tännsjö (2019): 128.

${ }^{30}$ Daniels (1985) and (2008). 
When resources are scarce and prioritization is mandatory, a maximin/leximin approach may prioritize treating people with severe health problems, such as cancer, diabetes or cardiovascular disease over granting non-standard reproductive services. I am not aware of any discussion of this issue from the viewpoint of prioritarianism, but I believe that prioritarianism should side with the maximin/leximin theory on this topic, granting priority to the unmet needs of people with life-threatening disease over the reproductive desires of couples and individuals. Together with prioritarianism's rejection of the 'repugnant conclusion', this seems to mark a significant difference between utilitarianism on the one hand, and the maximin/leximin theory and prioritarianism on the other.

Another point at which the normative theories discussed by Tännsjö may seem to depart from one another is the treatment of people with chronic illness or disability. As has long been noted, utilitarianism's emphasis on the use of QALYs has undesirably unfair consequences, which, seen from the perspectives of maximin/leximin theory, egalitarianism or prioritarianism, require correction. ${ }^{31}$ Imagine two patients suffering from the same medical condition, who can receive the same benefit from the available treatment; assume that the only difference between them is that one is otherwise healthy, and the other suffers from a chronic disease (say, Down's syndrome, diabetes or paraplegia). In such a case, utilitarianism would prioritize treating the former, since this would guarantee an increase in expected life years from 0.8 to 1 QALY, while treating the other for the same condition would guarantee an increase, say, from 0.5 to 0.7 QALY per year. If we multiply this value by the number of years the two patients are expected to live, assuming that they are equal, the total sum of QALY saved by treating the chronically ill or disabled individual will be less. On the other hand, if we decided based on maximin/leximin or egalitarianism, we would grant priority to the treatment of the second patient, considering that such allocation would provide for a partial counterbalancing of the initial inequality. Now, what about prioritarianism? Of course, here everything depends on the weighted value of the increase in healthcare accorded to the second patient, whose condition before treatment is worse. But it seems to me that, if we accept a reasonable prioritarian adjustment of the value of the disabled individual's happiness, then in many situations prioritarianism will suggest treating the second patient. Therefore, while utilitarianism can be charged with having discriminatory implications for the disabled in most situations, the same does not hold for prioritarianism.

One last point on which the three (or four) theories can be thought to diverge is the consideration of such biomedical interventions as mood and cognitive enhancement. Tännsjö rightly observes that utilitarianism is very favorable to them: in fact, "people who tend to live, from a hedonistic point of view, less than optimal lives, stand much to gain from mood enhancement once it becomes available and safe. This would be a good utilitarian investment, of course." ${ }^{32}$ Even if making us more intelligent did not make us happier, more intelligent people could provide economic gains for society. Now, Tännsjö suggests that the maximin/leximin theory would concur with this, because it would indirectly benefit the worst off by providing additional resources to meet their needs.

\footnotetext{
${ }^{31}$ For classic suggestions to this effect, see Harris (1987); Brock (2009).

32 Tännsjö (2019): 155.
} 
But there is room for disagreement on this point: if resources are allocated to promote mood enhancement in healthy and moderately happy people, or to enhance cognitive capacities in healthy subjects, they may not be available for sick people who are severely suffering; this would not take such suffering seriously enough. And even though indirect benefits might accrue to the worst off, it seems that the theory would suggest prioritizing the pressing medical needs of patients over the satisfaction of such non-medical desires. ${ }^{33}$ And, since prioritarianism does take suffering more seriously than maximin theories, it would concur with such a conclusion: even if alleviating conditions of suffering for any kind of medical patients should provide lesser increments in happiness than mood enhancement, prioritarianism would choose to provide relatively minor benefits to those patients rather than biomedical enhancements to people who, while not living optimal lives, are not suffering from any disease or pain.

\section{Conclusions}

I have suggested that, contrary to Tännsjö's account, prioritarianism should be understood as an amendment to egalitarianism, rather than to utilitarianism. Since it clearly rejects valuing equality per se, however, prioritarianism is different from egalitarianism as well; considered as a fourth option in its own right, it seems to enjoy better prospects than any of the competing accounts. Such an account should also lead us to question the practical convergence that Tännsjö sees among these theories. The practical conclusions justified by maximin/leximin theory and utilitarianism, in fact, seem to diverge more often than Tännsjö's speculations would suggest, and, in most cases, prioritarianism seems not to side with the utilitarian conclusions.

\section{Bibliography}

Arneson R.J. (2000), "Luck Egalitarianism and Prioritarianism," Ethics 110 (2): 339-349.

Brock D.W. (2009), "Cost-Effectiveness and Disability Discrimination," Economics and Philosophy 25 (1): 27-47.

Broome J. (2004), Weighing Lives, Oxford University Press, Oxford.

Buchanan A., Brock D.W., Daniels N. and Wikler D. (2000), From Chance to Choice: Genetics and Justice, Cambridge University Press, New York.

Daniels N. (1985), Just Health Care, Cambridge University Press, New York.

Daniels N. (2008), Just Health. Meeting Health Needs Fairly, Cambridge University Press, Cambridge.

Fleurbaey, M. (2015), “Equality versus Priority: How Relevant Is the Distinction?,” Economics and Philosophy 31 (2): 203-217.

Fleurbaey M., Tungodden B., Vallentyne P. (2009), “On the possibility of nonaggregative priority for the worst off," Social Philosophy and Policy 26 (1): 258-285.

Harris J. (1987), "QALYfying the Value of Life," Journal of Medical Ethics 13 (3): 117-123.

Holtug N. (2007), "Prioritarianism," [in:] Egalitarianism: New Essays on the Nature and Value of Equality, N. Holtug, K. Lippert-Rasmussen (eds), Clarendon Press, Oxford: 125-156.

${ }^{33}$ For a Rawlsian defense of prioritizing therapies over enhancements, see Buchanan, Brock, Daniels and Wikler (2000). 
Jensen K.K. (2003), "What is the difference between (moderate) egalitarianism and prioritarianism?," Economics \& Philosophy 19 (1): 89-109.

Nagel T. (1978), "The Justification of Equality," Crítica: Revista Hispanoamericana de Filosofía 10 (28): 3-31.

Nagel T. (1991), Equality and Partiality, Oxford University Press, New York.

O’Neill M. (2012), "Priority, Preference, and Value," Utilitas 24 (3): 332-348.

Otsuka M., Voorhoeve A. (2009), "Why It Matters That Some Are Worse Off Than Others: An Argument Against the Priority View," Philosophy and Public Affairs 37 (2): 171-199.

Parfit D. (1997), "Equality and Partiality," Ratio 10 (3): 202-221.

Parfit D. (2011), On What Matters, vol. 1, Oxford University Press, Oxford.

Parfit D. (2012), “Another Defence of the Priority View," Utilitas 24 (3): 399-440.

Persson I. (2008) "Why levelling down could be worse for prioritarianism than for egalitarianism," Ethical Theory and Moral Practice 11 (3): 295-303.

Porter T. (2011), "Prioritarianism and the Levelling Down Objection," Ethical Theory and Moral Practice 14 (2): 197-206.

Rabinowicz W. (2002), “Prioritarianism and Uncertainty: On the Interpersonal Addition Theorem and the Priority View," [in:] Exploring Practical Philosophy: From Action to Values, D. Egonsson, J. Josefsson, B. Petersson, T. Ronnow-Rasmussen, I. Persson (eds), Ashgate, Aldershot (UK): 139-165.

Segall S. (2016), Why Inequality Matters: Luck Egalitarianism, Its Meaning and Value, Cambridge University Press, Cambridge.

Sidgwick H. (1981), The Methods of Ethics, Hackett Publishing Company, Indianapolis/ Cambridge.

Tännsjö T. (2019), Setting Health-Care Priorities: What Ethical Theories Tell Us, Oxford University Press, New York. 